\title{
Árvores geneticamente modificadas: técnicas, aplicações, riscos e os potenciais impactos associados a sua utilização
}

\author{
Erlon Barbosa Valdetaro1, Ana Paula Vilela Carvalho', Otávio Surian Gamba1, \\ Michelle de Sales Moreira Demolinari ${ }^{1}$, Elias Silva ${ }^{1}$
}

1Universidade Federal de Viçosa, Av. Peter Henry Rolfs s/n, 36570-000, Viçosa, MG, Brasil, erlon.valdetaro@ufv.br; ana.vilela@ufv.br; otavio.
gamba@ufv.br; michelle.demolinari@ufv.br; eshamir@ufv.br

Resumo - As espécies florestais possuem grande importância, oferecendo diversos produtos madeireiros e não madeireiros fundamentais para a sociedade. Neste contexto, a busca de novas tecnologias capazes de promover incremento na produtividade das florestas comerciais tem merecido grande atenção, sendo que a biotecnologia tem contribuído substancialmente para isso. Este ramo da ciência pode promover a modificação direta do genoma de um organismo alvo, por meio da análise e manipulação do DNA ou pela inserção de fragmentos do mesmo com função conhecida e, deste modo, alcançar características previamente desejadas, tais como resistência a doenças e ataques de pragas, redução do teor de lignina na madeira e geração de plantas tolerantes a diferentes tipos de estresse. Esta revisão objetiva relatar técnicas para a geração de árvores geneticamente modificadas, aplicações da transformação genética em essências florestais, riscos do uso desta tecnologia e seus potenciais impactos ambientais.

Termos para indexação: Transgênico, biotecnologia, setor florestal, impacto ambiental.

\section{Genetically modified trees: techniques, applications, risk and potential impacts associated with their use}

\begin{abstract}
Forest species have great economic and social importance, offering various products as wood and non-timber fundamental to society. In this context, the search for new technologies that promote increase in productivity of commercial forests has received special attention and biotechnology has contributed substantially to this. This branch of science can promote direct modification of the genome of a target organism, through the analysis and manipulation of DNA genome or by insertion of fragments of the same with known function and thus to achieve desired characteristics, such as resistance to diseases and pests, lignin reduction in wood and generation of plants tolerant to different kinds of stresses. This review aims at reporting techniques for the generation of genetically modified trees, applications of genetic transformation in forest species, risks of using this technology and its potential environmental impacts.
\end{abstract}

Index terms: Transgenic, biotechnology, forestry, environmental impact.

\section{Introdução}

A busca de novas tecnologias capazes de aumentar a produtividade das florestas comerciais tem merecido destaque, notadamente no que se refere aos avanços biotecnológicos. A biotecnologia é o grupo de tecnologias que implicam na modificação direta do genoma de um organismo alvo por meio da análise e manipulação de DNA ou inserção de fragmentos do mesmo com função conhecida (Costanza \& Mccord, 2009).

Visando ao aperfeiçoamento das florestas, a biotecnologia utiliza diversas técnicas, dentre elas, a clonagem e a cultura de tecidos e possui importantes aplicações tais como a resistência de plantas às pragas e doenças, desenvolvimento de plantas adaptadas a situações de estresse e transgenia (Foelkel, 2009). O uso da biotecnologia traz avanços no melhoramento das plantas visando à maior produtividade das florestas em condições adversas para seu bom desenvolvimento como solos pobres em nutrientes, salinos ou com déficit hídrico.

A engenharia genética é responsável pela alteração da expressão de genes nativos, por meio da inserção de um promotor que poderá causar aumento ou diminuição 
da expressão de um gene de interesse. Esta técnica pode ser utilizada para aumentar o crescimento das árvores, controle de floração e modificar a composição da madeira. É responsável, também, pela inserção de genes de interesse em plantas (transgenia) com base na transferência de DNA para uma célula vegetal-alvo, sendo incorporado no genoma da nova planta e expresso de forma estável (Brasileiro \& Dusi, 1999).

De acordo com Rautner (2001), no período de 1988 a 2000 existiam aproximadamente 252 testes em campo com plantas lenhosas transgênicas, envolvendo, pelo menos, 24 espécies vegetais em 17 países. Destas, 51\% são realizados com lenhosas do gênero Populus, seguido por Pinus com $23 \%$, Liquidambar com $11 \%$ e Eucalyptus com 7\% (Sartoretto et al., 2008). Os principais países condutores deste tipo de teste são: Estados Unidos, França, Indonésia, Itália, Reino Unido, Chile, África do Sul, Nova Zelândia e China (Owusu, 1999).

Uma das grandes contribuições observadas na transferência de genes no setor florestal seria minimizar as limitações do melhoramento tais como o longo tempo para obtenção de novas gerações e a grande variabilidade existente entre e dentro de espécies (Diciero \& Amaral, 2002).

$\mathrm{Na}$ área florestal, a biotecnologia tem mostrado relevantes avanços. Contudo, esses avanços podem ser muito lentos devido à complexidade da estrutura genética da planta. Segundo Constanza \& McCord (2009), o DNA de uma árvore de Pinus taeda é cerca de sete vezes maior que o DNA humano. Ademais, o efeito na expressão de outras características, além das que são alvo do processo de transformação, nas plantas transgênicas obtidas, ainda é pouco conhecido (Silva, 2009).

O presente trabalho relata as técnicas para geração de árvores geneticamente modificadas, aplicações da transformação genética em essências florestais, riscos do uso desta tecnologia e seus potenciais impactos ambientais, socioeconômicos e culturais.

\section{Estratégias para a obtenção de plantas transgênicas}

Três etapas fundamentais são necessárias para o sucesso na transferência de genes: identificação, isolamento e introdução do gene de interesse no DNA da planta; identificação, seleção e crescimento das células transformadas; e utilização de um sistema de regeneração das células transformadas.
Para selecionar os genes de interesse e as células transformadas, geralmente são usados genes marcadores de seleção. Esses marcadores conferem características ímpares às células transformadas, como: resistência a determinados agentes seletivos (antibióticos e herbicidas) e codificação de enzimas específicas. Atuando junto aos genes marcadores, células e tecidos podem ser identificados pela expressão de genes repórteres ou marcadores, onde estes codificam proteínas geralmente de atividades enzimáticas com produtos de fácil identificação (Sartoretto et al., 2008). Em espécies florestais, os genes repórteres mais utilizados são o gene uidA, que codifica a enzima ß-Glucuronidase (GUS) (Jefferson et al., 1987), e o gene $g f p$ que codifica a Green Fluorescent Protein (GFP) (Chalfie et al., 1994).

Atualmente, diferentes sistemas de transferência de gene estão sendo utilizados nos mais diferentes ramos de atuação. No cenário florestal, as estratégias com maiores destaques são o método indireto, baseado na patogenicidade de Agrobacterium e os métodos diretos, os quais dispensam o uso deste vetor intermediário (Babu et al., 2003).

\section{Método indireto}

\section{Estratégia via Agrobacterium}

A transferência de genes mediada por Agrobacterium tumefaciens tem se revelado um veículo altamente versátil. Agrobacterium tumefaciens é o agente etiológico da doença galha-da-coroa, que em espécies infectadas provoca o aparecimento de tumores entre o caule e a raiz. Para isso, a bactéria transfere genes contidos em uma região específica do plasmídeo $\mathrm{Ti}$ (indutores de tumor), denominada T-DNA, sendo responsável pela transferência de DNA e os sintomas da doença. Nessa região existem inúmeros genes, entre eles, os oncogenes, responsáveis pela patogenicidade da bactéria. Os únicos genes indispensáveis para que ocorra o processo de transferência e integração da fita-T são cadeias de sequência de genes situados nas extremidades direita e esquerda do T-DNA (Gasser \& Fraley, 1989).

Sendo assim, há possibilidades de utilizar linhagens de Agrobacterium como vetores no processo de transformação de plantas. Para tal, são excluídos os oncogenes, obtendo-se uma linhagem "desarmada" e o vetor é inserido entre as extremidades da região-T (Sartoretto et al., 2008). 
Os vetores utilizados por este sistema podem ser binários ou cointegrados. Os binários são menos estáveis do que os cointegrados, porém o uso deste vetor é superior devido a sua facilidade de manipulação genética e a baixa recombinação dos cointegrados (Brasileiro \& Dusi, 1999).

Diversos estudos têm mostrado a eficiência da transferência de gene via Agrobacterium, em muitas áreas afins. Spokevicius et al. (2005), trabalhando com eucalipto, demonstraram a possibilidade de transferir genes com altos níveis de estabilidade, utilizando como técnica adjacente cultura de tecidos in vitro. Prakash \& Gurumurthi (2009) desenvolveram uma metodologia eficiente para transferência de gene em Eucalyptus tereticornis usando explantes de cotilédones e hipocótilos, concluindo que a metodologia proposta atingiu excelentes resultados. Yevtushenko \& Misra (2010) mostraram a eficiência da transferência de genes via Agrobacterium em híbridos de Populus (Populus nigra L. X P. maximowiczii).

\section{Método direto}

\section{Estratégia via biobalística}

Esta técnica de transferência de genes em células ou tecidos vegetais data do início da década de 1980. O método consiste na aceleração de micro partículas que atravessam a parede celular e a membrana plasmática, de forma não letal, carreando substâncias adsorvidas como DNA, RNA ou proteínas para o interior da célula (Klein et al., 1987; Sanford et al., 1987). São utilizados microprojéteis de ouro ou tungstênio, com diâmetro em torno de $1 \mu \mathrm{m}$, nos quais são precipitadas as moléculas de DNA. O tipo de aparelho usado para acelerar as micropartículas envolvidas pelo DNA pode ter propulsão a ar, pólvora, gás hélio ou eletricidade, e os genes entram nas células juntamente com o projétil e se integram ao genoma celular (Klein \& Fitzpatrick-McElligott, 1993).

Diversos parâmetros físicos e biológicos devem ser levados em consideração para se estabelecer um protocolo de transformação utilizando-se esse método, tais como a espécie vegetal e seu estado fisiológico, o tipo de explante, tipo e tamanho da partícula, método de precipitação, velocidade das partículas e o tipo de equipamento (Sanford et al., 1993).

Inúmeros trabalhos apontam para a efetividade desta técnica de transferência de gene no meio florestal.
Ferreira et al. (2004), trabalhando com cupuaçu, (Theobroma grandiflorum), utilizaram gás hélio como propulsor em diferentes pressões, concluindo ser um mecanismo eficiente para a transferência de genes para essa cultura, desde que a pressão esteja entre 650 psi e 1.000 psi. Quoirin et al. (2002) utilizaram a biobalística para transferência de genes em duas espécies de acácia (Acacia sp.), porém a metodologia utilizada teve resultados satisfatórios apenas para uma das espécies. Castellanos-Hernandez et al. (2009) utilizaram mecanismos baseados em biobalística, com variação de pressão, em Paulownia elongata, acompanhando desde a transferência do gene até o estabelecimento da cultura em estufas. As condições ótimas encontradas foram próximas de 450 psi. Serrano et al. (1996) conseguiram ótimos resultados em transferência de genes por biobalística em eucalipto (Eucalyptus globulus), utilizando embriões zigóticos como células-alvo. Li et al. (2009), com trabalho semelhante, obtiveram sucesso na técnica utilizando células-alvo de Populus sp.

Para Santarém (2000), os métodos de transferência de genes podem variar em eficiência e aplicabilidade, dependendo da espécie e/ou do tecido alvos da transformação. Entre os métodos diretos mais usados, o bombardeamento de partículas tem resultado no maior número de espécies transformadas, principalmente nos cereais, em que a transformação por Agrobacterium é pouco eficiente. O uso de Agrobacterium como vetor para a transferência de genes apresenta vantagens sobre os métodos diretos por ser uma metodologia mais precisa, resultando na integração de um menor número de cópias do transgene.

\section{Aplicações da transformação genética em espécies florestais}

A introdução da biotecnologia no setor florestal representa uma importante ferramenta para o melhoramento genético e contribui para ganhos em produtividade e sustentabilidade. Os benefícios a partir de organismos geneticamente modificados na silvicultura são mais do que a melhoria no crescimento e forma das árvores, incluindo também benefícios potenciais na melhoria das características das mesmas (Balocchi \& Valenzuela, 2004). São exemplos atuais destas características florestais que vêm sendo aplicadas e melhoradas por meio da transgenia: 


\section{Redução do teor e composição da lignina}

Entre as características de madeira de qualidade que agora podem ser alteradas por modificação genética estão a composição e as propriedades de processamento de ligninas. A extração de lignina pela indústria de polpa e celulose não é apenas um processo caro, mas também gera grandes quantidades de resíduos químicos. Desta forma, tem sido sugerido pela engenharia genética modificar as vias metabólicas envolvidas na biossíntese de lignina, a fim de desenvolver árvores transgênicas com propriedades de polpa já melhoradas. As árvores transgênicas resultantes têm enorme valor para a silvicultura (Studart-Guimarães et al., 2003).

Usando a tecnologia antisense para reduzir a expressão de 4-coumarate: coenzima A ligase, uma etapa chave na biossíntese de lignina, observaram-se reduções de até $45 \%$ no teor de lignina e aumento de até $15 \%$ no teor de celulose que foram obtidos em Populus tremuloides e P. tremula (Gartland et al., 2003).

Esta técnica pode ser utilizada em eucalipto no Brasil, onde esta espécie é a maior fonte de matériaprima para a produção de celulose e, em plantios comerciais, apresenta baixa variabilidade natural. Entretanto para outras espécies florestais essa técnica não é recomendada, devido a alta variabilidade natural. A variabilidade genética existente na população a ser melhorada, constitui a matéria-prima, sobre a qual são realizados os processos de seleção e melhoramento (Muro-Abad, 2000).

\section{Resistência a pragas e doenças}

Espécies florestais e inúmeras plantas são alvo de ataques por insetos que causam injúrias aos tecidos vegetais, podendo agir como vetores de transmissão de doenças, prejudicando o desenvolvimento da planta e, consequentemente, diminuindo sua produtividade. $\mathrm{O}$ controle de insetos por pesticidas nas diversas espécies tem como grande desvantagem ser altamente tóxico para o homem e para o meio ambiente e, devido à grande área de cultivo, onerar o custo da produção (StudartGuimarães et al., 2003).

O pesticida biológico atualmente mais utilizado em organismos geneticamente modificados tem como princípio ativo um inseticida natural isolado de Bacillus thuringiensis $(B t)$ que atua formando cristais durante a esporulação do bacilo, denominados cry (Crystal proteins $(I C P s)$ ), capazes de perfurar o intestino de insetos após sua ingestão (Tang \& Newton, 2003).
Os genes que codificam as proteínas formadoras de cristais, denominados cry, estão sendo introduzidos em plantas transgênicas anuais de interesse econômico e, mais recentemente, também em lenhosas. Plantas transgênicas de álamo (Populus nigra), expressando o gene inseticida de Bacillus thuringiensis, foram obtidas por Wang et al.(1996), e demonstram resistência a Apochemia cineraius e Lymantria dispar.

Também são conhecidas plantas de Pinus taeda expressando os genes crylAc e Bt. Também plantas de Eucalyptus camaldulensis foram transformadas via Agrobacterium contendo o gene cry $3 A$, mostrando resistência à Chrysophtharta bimaculata, uma importante praga em suas plantações (Sartoretto et al., 2008).

\section{Tolerância à herbicida}

Os herbicidas são ferramentas essenciais nos plantios de espécies tanto agrícolas quanto florestais, permitindo um aumento na produtividade pela diminuição do surgimento de ervas que competem com as espécies por nutrientes do solo, água e luz. Plantas tolerantes a herbicidas reduzem a necessidade de aplicação de diversos herbicidas, favorecem a aplicação de produtos menos impactantes, menos tóxicos ao meio ambiente e ao homem e também reduz os gastos do produtor com este tipo de operação (Balocchi \& Valenzuela, 2004).

Genes que conferem tolerância a herbicidas como o aro $A$ mutado, quando expressos, agem detoxificando os herbicidas aplicados e permitem o desenvolvimento normal da planta transgênica e a eliminação de ervas daninhas (Studart-Guimarães et al., 2003).

O híbrido Populus tremula x Populus alba foi posteriormente transformado com o gene $\operatorname{crs} 1-1$, isolado de um mutante de Arabidopsis thaliana que codifica a enzima Acetatolactato Sintase, conferindo tolerância ao herbicida clorosulfuron (Brasileiro et al., 1992).

\section{Produção de biomassa}

A alta produtividade no setor florestal está relacionada ao aumento da taxa de crescimento, ao volume do tronco e à qualidade da madeira das espécies florestais, que são características de importância econômica e desejáveis para a obtenção de celulose e papel. A alteração dos níveis dos hormônios nas células vegetais implica no conhecimento do seu modo de ação no crescimento e desenvolvimento das plantas (Sartoretto et al., 2008).

Um gene isolado de Arabidopsis, o qual é essencial na via de biossíntese da giberelina (GA), que codifica para a GA20-oxidase, foi superexpressado por Eriksson 
et al. (2000), em plantas transgênicas do híbrido Populus tremula x $P$. tremuloides. As plantas apresentaram maior crescimento em diâmetro e altura, folhas maiores, fibras do xilema mais numerosas e maiores e, consequentemente, aumento da produção de biomassa.

\section{Remoção de poluentes - Fitorremediação}

A fitorremediação é uma tecnologia de grande importância, uma vez que utiliza plantas que acumulam, degradam ou removem contaminantes do solo, tornando estas áreas menos poluídas (Rishi et al., 2001).

No trabalho desenvolvido por Rugh et al. (1998), foram obtidas árvores transgênicas para fitorremediação de mercúrio. Por exemplo, o Liriodendron tulipifera foi transformado com o gene merA, modificado, da linhagem BL308 de Escherichia coli, o qual codifica a mercúrio reductase, tornando-se capaz de reduzir mercúrio altamente tóxico $\left(\mathrm{Hg}^{2+}\right)$ em sua forma menos tóxica e volátil $(\mathrm{Hg})$.

Gordon et al. (1998) discutiram o uso de plantas do gênero Populus como indicadas em aplicações comerciais de fitorremediação, sendo utilizadas na remoção de metais e compostos orgânicos, como no caso do Trichloroethylene (TCE), químico (potencialmente cancerígeno) que não ocorre naturalmente no ambiente.

Organismos geneticamente modificados na silvicultura também contribuem para a recuperação dos solos por meio da reciclagem de metais pesados (Balocchi \& Valenzuela, 2004).

\section{Absorção de fósforo}

Além das características já citadas, o setor florestal tem desenvolvido materiais genéticos com maior eficiência nutricional. Para que ocorra maior eficiência na absorção de fósforo, uma das estratégias é o aumento da exsudação do citrato. Suzuki et al. (2003), por meio do emprego da biotecnologia, aumentaram significativamente a exsudação de ácidos orgânicos em plantas de Eucalyptus grandis $x E$. urophylla que superexpressam o gene da citrato sintase (CS) em condições de alta acidez do solo e baixa disponibilidade de fósforo, contribuindo assim para uma maior eficiência na absorção deste elemento.

O efeito da transformação genética para absorção de fósforo no crescimento e eficiência nutricional foi avaliado por Silva (2009), em um clone de Eucalyptus grandis $X$ E. urophylla. As plantas transformadas e não transformadas para a superexpressão do gene que codifica a citrato sintase (CS) foram cultivadas em solo enriquecido com doses de fósforo $(0,45$ e $90 \mathrm{mg}$ $\mathrm{dm}^{-3}$ ), com e sem calagem. O material geneticamente modificado apresentou maior incremento inicial em altura e em diâmetro do colo quando cultivado sem calagem e na dose zero de fósforo; também apresentou aumento no número de folhas e área foliar.

\section{Riscos potenciais do uso de árvores geneticamente modificadas (GM)}

Juntamente com a divulgação das pesquisas com árvores geneticamente modificadas surgem os receios da sociedade com relação às mesmas. Estes receios tornamse ainda maiores quando se fala sobre a introdução destas árvores no meio ambiente, especialmente relacionado às características que podem lhe dar uma melhor adequação, como o rápido crescimento e a resistência a pragas e doenças.

Para o caso das plantações florestais, é evidente que se oferece um risco muito baixo para a saúde humana e a segurança alimentar (Valenzuela et al., 2006). Entretanto, uma das preocupações mais comuns é o potencial para a disseminação de genes de resistência a antibióticos ou herbicidas para outras espécies não alvo (Gartland et al., 2003).

De acordo com Freire et al. (2002), fluxo gênico é um processo migratório de alelos entre populações. O efeito da migração de alelos entre populações da mesma espécie depende da proporção de indivíduos migrantes e da diferença nas frequências do alelo nas duas populações. A seleção natural poderá atuar a favor de elevar frequências de alelos introduzidos, caso eles confiram alguma vantagem seletiva aos indivíduos portadores dos mesmos.

Isto pode ocorrer de várias maneiras, incluindo a transferência de transgenes através da polinização ou a hibridização de organismos geneticamente modificados com parentes naturais (Constanza \& Mccord, 2009).

Um ponto comumente analisado é a mudança na aptidão associada com a característica introduzida ou o transgene. Para o caso de culturas geneticamente modificadas, a maioria das características introduzidas é de um único gene, por exemplo, a tolerância a herbicidas e resistência a insetos (Valenzuela et al., 2006). Para o caso específico da área florestal, Meilan et al. (2002) afirmam que existem várias espécies de árvores geneticamente modificadas que são tolerantes a herbicidas e que já foram testadas em campo. Os mesmos autores concluem ainda que para as características de 
grande valor econômico na silvicultura, as árvores GM exigirão a introdução (ou supressão) de muitos genes e que características desejadas como tolerância ao estresse, os baixos níveis de lignina e outros dependem de um caminho bioquímico e, portanto, a presença do traço fica relacionada a um complexo de genes.

Constanza \& McCord (2009) elencam, independentemente da quantidade de transgene em uma determinada espécie de árvore GM, os potenciais riscos do uso destas árvores, além do fluxo gênico:

Competição com indivíduos naturais em decorrência do fitness excepcional - Mesmo que uma das principais metas seja produzir árvores em melhores condições de prosperar no ambiente, existem preocupações de que estas árvores mais adaptadas biologicamente possam afastar espécies nativas. Há a chance da árvore GM excepcionalmente ajustada ao ambiente manter os seus parentes nativos em condições de crescimento inferior ao seu, reduzindo as chances naturais de crescimento dos indivíduos nativos.

Efeitos sobre as espécies não alvo - Possíveis efeitos de espécies não alvo podem incluir danos aos organismos benéficos do solo, insetos, aves ou outras plantas. Como exemplo, podemos usar o caso do gene Bt que é a alteração genética mais comum em plantas, produzindo uma proteína tóxica a alguns insetos-praga. É possível que os álamos Bt plantados na China possam inadvertidamente prejudicar uma espécie não alvo dos insetos. Havendo um aprimoramento e uma boa gestão das árvores com o gene $\mathrm{Bt}$, dada a rigorosa investigação sobre o gene, esta situação torna-se extremamente improvável, mas ainda assim não deixa de ser uma preocupação.

Efeitos na biodiversidade - Estas preocupações envolvem as inter-relações entre as espécies florestais que afetam um ecossistema inteiro. As árvores estéreis da engenharia genética poderiam não apoiar a diversificação das espécies de uma população em um ecossistema. Outra preocupação é que a função de destino da árvore de biotecnologia terá consequências não intencionais no ecossistema. Ou seja, uma árvore GM contendo um gene que inadvertidamente afeta espécies não alvo ou ainda não havendo fluxo gênico de árvores nativas, contribui para a ocorrência de efeitos negativos para a biodiversidade.

Com uma preocupação mais voltada para a tentativa de redução dos riscos de fuga de transgênicos, vários métodos de mitigação têm sido propostos (UNEP,
2008). Esses métodos são semelhantes às tecnologias de restrição de uso genético (GURT), que já foram propostas para a utilização em culturas agrícolas. Mathews \& Campbell (2000) citam como alternativas para evitar a propagação de árvores GM a interrupção da produção de pólen, ou floração da árvore, e o retardo da maturidade sexual, para que estas árvores sejam colhidas antes da polinização, mas estas técnicas não teriam nenhum efeito sobre a transferência não sexual do material transgênico, como exemplo da reprodução vegetativa.

Farnum et al. (2007) acreditam que através da eliminação de pólen e flores, uma grande parte da cadeia alimentar seria interrompida com o impedimento da produção de frutos e nozes.

De acordo com Brunner et al. (2007), os métodos para evitar fugas de transgenes de árvores geneticamente modificadas podem ser divididos em cinco abordagens principais: mitigação (ligando todas as prestações de sobrevivência de transgenes para genes que só são benéficas sob exploração ou configurações de plantio); a excisão (remoção dos transgenes de gametas antes do lançamento da árvore); a supressão do gene (comprometendo proteínas, DNA ou níveis de RNA, dos genes essenciais para a reprodução); ablação (destruição dos tecidos florais com o uso de citotoxina); e a repressão (adiamento da floração). Os mesmos autores citam ainda que dado o alto nível de compreensão das árvores geneticamente modificadas e os estudos genômicos e tecnológicos que tenham sido realizados, ainda não é possível determinar o método mais eficaz de contenção de árvores transgênicas, nem a confiabilidade dos métodos desenvolvidos até o momento, sendo imprudente confiar que os transgenes poderiam ser completamente contidos sem mais estudos sobre o assunto. Entretanto, a recente descoberta da tecnologia do gene Deletor modificado geneticamente, que provou ser eficaz no fornecimento de $100 \%$ de contenção no setor do tabaco, sugere que o fluxo de genes através da reprodução sexual poderia ser evitado (Luo et al., 2007).

Para Valenzuela \& Strauss (2005), os ensaios de campo de árvores GM não têm sido capazes de durar mais de seis anos, devido ao boicote de vários grupos ambientalistas e aos diferentes tipos de certificação, como a Forest Stewardship Council (FSC), que proibiram o uso de árvores geneticamente modificadas, mesmo sob condições de confinamento. 
Como atualmente não há um conjunto de práticas que possam assegurar a gestão em longo prazo das árvores geneticamente modificadas, o Institute of Forest Biotechnology (IFB), uma organização sem fins lucrativos presente em todo o mundo e que aborda a sustentabilidade da biotecnologia florestal em escala global, criou o "Uso responsável: Princípios da Biotecnologia Florestal"; uma iniciativa para desenvolver essas práticas críticas em um ambiente altamente transparente e multilateral de processos dirigidos (IFB, 2010).

O uso responsável estabelece práticas que podem ser usadas para complementar os sistemas de certificação ou de programas de regulamentação, e cria material didático que orienta estudantes e pesquisadores envolvidos com a ciência da biotecnologia. Não deve ser visto como um mecanismo de certificação. Também não é projetado para substituir qualquer mecanismo de regulação em qualquer país. Em vez disso, é projetado para substituir a atual gestão e as práticas de regulamentação através dos princípios que proporcionam alto nível de orientação e práticas, sendo acionáveis por qualquer usuário de árvores transgênicas e verificável por outros mecanismos de controle.

\section{Potenciais impactos ambientais, culturais e socioeconômicos}

Para cada uso específico das árvores GM, é possível elencar um ou mais impactos ambientais, culturais ou socioeconômicos. Os potenciais impactos devem ser considerados positivos quando resultarem em um ou mais benefícios para a saúde e o bem-estar da população humana e dos ecossistemas e devem ser considerados negativos quando resultarem em uma desvantagem ou uma ameaça para estes mesmos parâmetros (UNEP, 2008).

\section{Potenciais impactos ambientais positivos}

A redução do teor de lignina pode diminuir a necessidade de produtos químicos e a quantidade de energia necessária para o processamento de celulose (Mathews \& Campbell, 2000; Johnson \& Kirby, 2001).

A necessidade de aplicação de pesticidas de amplo espectro em áreas florestais pode ser reduzida por causa da característica de resistência a insetos (James et al., 1998; Mathews \& Campbell, 2000).
Árvores com maior tolerância ao estresse poderiam ser utilizadas na fitorremediação de solos contaminados (van Frankenhuyzen \& Beardmore, 2004).

De acordo com Golle et al. (2009), a propagação clonal via miniestaquia merece especial destaque frente ao seu amplo uso e aos excelentes resultados obtidos, porém técnicas como a Cultura de Tecidos, Marcadores Moleculares e Transformação Genética são cada vez mais importantes, dando suporte aos programas de Melhoramento. Técnicas essas que passarão, cada vez mais, a integrar as rotinas dos programas de melhoramento, com sucesso no Brasil.

$\mathrm{O}$ aumento da produtividade de árvores geneticamente modificadas também pode reduzir o consumo de madeira nativa, por meio do consumo das plantações de alto rendimento (Strauss et al., 2001).

\section{Potenciais impactos ambientais negativos}

A redução do teor de lignina pode tornar árvores mais vulneráveis a doenças virais (van Frankenhuyzen $\&$ Beardmore, 2004). Os mesmos autores consideram ainda que as árvores com níveis mais baixos de lignina podem afetar a estrutura e a química do solo, permitindo a aceleração das taxas de decomposição.

A resistência a insetos pode reduzir o número de fitófagos e a pólen-alimentação de insetos presentes em uma floresta (Johnson \& Kirby, 2001).

Existe a possibilidade de que as novas características que entram no ecossistema afetem os processos biotróficos do ecossistema hospedeiro (Mathews \& Campbell, 2000).

A adaptabilidade de formações florestais e de plantações para estresse biótico ou abiótico pode diminuir devido à utilização de clones (Carnus, 2006).

\section{Potenciais impactos socioeconômicos positivos}

$\mathrm{O}$ aumento do teor de lignina das árvores levaria a uma maior densidade da madeira e, consequentemente, a uma melhor qualidade e maior valor do produto. Também seria elevado o valor calórico da madeira, servindo como fonte de combustível mais eficiente. Aumentaria também a resistência da madeira, permitindo o desenvolvimento de materiais de construção mais resistentes. Todas estas características podem agregar maior valor de mercado à madeira geneticamente modificada (Mathews \& Campbell, 2000). Os mesmos autores citam ainda que árvores resistentes a pesticidas podem reduzir a necessidade do uso destes produtos, diminuindo, deste modo, o custo de produção, possibilitando a obtenção de maiores lucros.

Pesq. flor. bras., Colombo, v. 31, n. 65, p. 51-61, jan./mar. 2011 
Com menos ervas daninhas presentes nos plantios, dada a resistência à aplicação de herbicidas pelas árvores, pode haver uma menor competição por recursos e os indivíduos seriam capazes de crescer de forma mais eficiente e consequentemente teriam maior produtividade (Johnson \& Kirby, 2001).

As espécies economicamente valiosas poderiam ser projetadas de tal forma que poderiam ser cultivadas em vários locais fora da sua área de uso tradicional, permitindo uma maior produção e uma redução na quantidade de tempo necessária para a produção de melhores fenótipos (Mathews \& Campbell, 2000).

Árvores GM com características de resistência às condições adversas de crescimento poderiam ser plantadas em solos onde tradicionalmente não têm sido capazes de sobreviver, permitindo a fitorremediação de solos contaminados e criando um meio rentável de restaurar a terra que de outra forma não poderia ser utilizada (Farnum et al., 2007).

\section{Potenciais impactos socioeconômicos negativos}

Uma árvore com níveis alterados de lignina pode ser menos viável do que suas contrapartes não modificadas e, portanto, poderia ter impactos econômicos negativos, como resultado da maior mortalidade de indivíduos (Mathews \& Campbell, 2000; van Frankenhuyzen \& Beardmore 2004).

Os produtores pobres dos países em desenvolvimento podem não ter acesso a árvores geneticamente modificadas, dado o seu custo relativamente elevado, excluindo-os de certos mercados e privando-os do acesso a novos tipos de sementes (Thomas, 2001).

No caso de espécies, consideradas como pragas, tornarem-se resistentes aos métodos químicos e biológicos de controle em vigor atualmente, o custo com controle destas pragas aumentaria (Mathews \& Campbell, 2000).

O longo período de tempo entre o começo dos projetos de investigação sobre árvores geneticamente modificadas e quando os benefícios começam a ser gerados faz da árvore GM uma proposta econômica arriscada (van Frankenhuyzen \& Beardmore, 2004).

Em relação ao desenvolvimento da engenharia genética no setor florestal brasileiro, verifica-se que a produção de árvores transgênicas será comercialmente atrativa somente caso os genótipos geneticamente modificados possam ser propagados em larga escala e a baixos custos. Observa-se nos trópicos condições que facilitam a propagação de espécies folhosas como eucaliptos e gmelinas, dentre outras. Entretanto, diversas espécies ainda não são propagadas facilmente quando o seu conteúdo genético é modificado, apresentando alto custo de propagação em larga escala. Assim sendo, quando combinado o melhoramento clássico e as novas ferramentas da engenharia genética em árvores geneticamente modificadas, pode exigir um longo período de tempo antes que estas possam ser multiplicadas em larga escala. Deste modo, devido aos altos custos e tempo exigidos, a utilização da transferência de genes limitaria o seu uso comercial (Di Ciero \& Amaral, 2002).

\section{Potenciais impactos culturais positivos}

A modificação genética pode contribuir para a proteção e conservação das espécies culturalmente importantes, que têm estado em declínio, como resultado de doença (Farnum, 2007).

\section{Potenciais impactos culturais negativos}

O desenvolvimento não intencional de espécies resistentes a insetos e a herbicidas, como resultado de escape do transgene, pode alterar composições florísticas e reduzir o número daquelas presentes em determinado local, obrigando as sociedades a se adaptarem às mudanças nas condições de biodiversidade (Peterson et al., 2000).

A modificação genética pode tornar os sistemas locais menos adaptáveis e algumas sociedades dependentes de insumos externos (Peterson et al., 2000).

\section{Considerações finais}

Dada a importância do setor florestal para a sociedade, é crescente o número de pesquisas voltadas para o melhoramento genético das espécies florestais de grande valor econômico.

A pesquisa na área de modificação genética de árvores, assim como de outras culturas agrícolas, sofre grande pressão ambiental devido aos potenciais riscos que a tecnologia oferece. Porém, é preciso mais pesquisas com estas árvores no campo, e com um tempo de avaliação maior, para uma análise justa sobre os reais riscos oferecidos pela tecnologia e alternativas de controle dos mesmos.

É preciso considerar que o uso da tecnologia de árvores geneticamente modificadas também oferece impactos ambientais, culturais e socioeconômicos de caráter positivo e que devem ser igualmente considerados na avaliação que se faz sobre o uso deste tipo de tecnologia. 
As pesquisas com árvores geneticamente modificadas tendem a aumentar, em todo o mundo, devido ao retorno econômico que a tecnologia oferece, bem como a possibilidade do uso destas árvores para a recuperação de áreas ambientalmente degradadas e a possibilidade de adaptação de espécies em ambiente que oferece alguma condição de adversidade ao cultivo.

Entretanto, há muitas questões que devem ser resolvidas e melhor entendidas cientificamente em relação ao desenvolvimento de espécies geneticamente modificadas em diferentes condições ambientais de temperatura, disponibilidade de água e luz.

\section{Referências}

BABU, R. M.; SAJEENA, A.; SEETHARAMAN, K.; REDDY M. $\mathrm{S}$. Advances in genetically engineered (transgenic) plants in pest management-an over view. Crop Protection, v. 22, p.1071-1086, 2003.

BALLOCCHI, C.; VALENZUELA, S. Introduction to GMOs and Biosafety in Forestry. Workshop Biotecnologia Forestal. p. 87-98, 2004. Disponível em: http://www.forestbiotech.org/pdf/ ChlePDFfinal31Jan2005.pdf>. Acesso em: 16 mar. 2010.

BRASILEIRO, A. C. M.; DUSI, D. M. A. Transformação Genética de Plantas. In: TORRES, A. C; CALDAS, L. S.; BUSO, J. A. Cultura de Tecidos e Transformação Genética de Plantas. Brasília: Embrapa, 1999.

BRASILEIRO, A. C. M.; TOURNEUR, C.; LEPLE, J C.; COMBES, V.; JOUANIN L. Expression of the mutant Arabdopsis thaliana acetolactate synthase gene confers chlorsulfuron resistance to transgenic poplar plants. Transgenic Research, v.1, p.133-141, 1992.

BRUNNER, A. M.;LI, J. I.; DIFAZIO, S. P.; SHEVCHENKO, O.; MONTGOMERY, B. E.; MOHAMED, R.; WEI, H.; MA, C.; ELIAS, A. A.; VANWORMER, K.; STRAUSS, S. H. . Genetic containment of forest plantations, Tree Genetics \& Genomes, v. 3, n. 2, p. 75-100. 2007.

CARNUS, J. M.; PARROTTA, J.; BROCKERHOFF. E. G.; ARBEZ, M.; JACTEL, H.; KREMER, A.; LAMB, D.; O'HARA, K.; WALTERS, B. planted forests and biodiversity, journal of forestry, v. 104, n. 2, p. 65-77(13). Mar. 2006.

CASTELLANOS-HERNÁNDEZ, O. A. RODRÍGUEZSAHAGÚN, A.; ACEVEDO-HERNÁNDEZ, G. J.; RODRÍGUEZ-GARAY, B.; CABRERA-PONCE J. L.; HERRERA-ESTRELLA L. R. Transgenic Paulownia elongata S. Y. Hu plants using biolistic-mediated transformation. Plant cell, tissue, and organ culture v. 99, p. 175-181, 2009.

CHALFIE, M.; TU, Y.; EUSKIRCHEN, G.; WARD, W. W.; PRASHER, D. C. Green fluorescent protein as a marker for gene expression. Science, v. 263, p.802-805, 1994.
COSTANZA, A.; McCORD, S. Forest Biotechnology and its Responsible Use. Institute of Forest Biotechnology. 2009. Disponível em: www.responsibleuse.org/resources/biotechtrees. pdf. Acesso em: 10 abr. 2010.

DI CIERO, L.; AMARAL, W. Árvores geneticamente modificadas na silvicultura intensiva. Biotecnologia, Ciência e Desenvolvimento, Ano 5, n. 29, p.92-98, nov/dez. 2002.

ERIKSSON, M. E.; ISRAELSSON, M.; OLSSON, O.; MORITZ, $\mathrm{T}$. Increased gibberellins biosynthesis in transgenic trees promotes growth, biomass production and xylem fiber length. Nature Biotechnology, v. 18, p. 784-788, 2000.

FAO. Organizações das Nações Unidas para Agricultura e Alimentação. Relatório dos recursos florestais mundiais, 2010. Disponível em: http://www.fao.org.br/ddmcramp.asp

FARNUM, P.; LUCIER, A.; MEILAN, R. Ecological and population genetics research imperatives for transgenic trees, Tree Genetics \& Genomes, v. 3, n. 2, p. 119-133. 2007.

FERREIRA, M. G. R.; CARVALHO, C. H. S.; CARNEIRO, A. A.; CARDENAS, F. E. N. Introdução de genes em segmentos foliares de cupuaçu (Theobroma grandiflorum schumm.) usando biobalistica. Ciência Rural, Santa Maria, v. 34, n.1, p. 265-279, jan/fev. 2004.

FOELKEL, C. Plantações de eucalipto e árvores geneticamente modificadas. 2009. Disponível em: <http://www.eucalyptus.com. br/newspt_dez09.html\#quatorze.> Acesso em: 22 mar 2010.

FREIRE, E. C.; BARROSO, P. A. V.; PENNA, J. C. V.; BORÉM, A. Fluxo gênico:Análise do caso de algodão no Brasil.

Biotecnologia Ciência \& Desenvolvimento, Brasília - DF, ano 5, n. 29, p. 105-113, 2002.

GARTLAND, K. M. A.; CROW, R. M.; FENNING, T. M.; GARTLAND, J. S. Genetically modified trees: Production, Properties, and potential, Journal of Arboriculture, v. 29, n. 5, Sep. 2003.

GASSER, C. S.; FRALEY, R. T. Genetically Engineering Plants for Crop Improvement. Science, v. 244, n. 4910, p. 1293-1299, 1989.

GOLLE, D. P.; REINIGER, L. R.S.; CURTI, A. R. Melhoramento florestal: ênfase na aplicação da biotecnologia. Ciência Rural, Santa Maria, v.39, n.5, p.1606-1613, ago, 2009.

GORDON, M.; CHOE, N.; DUFFY, J.; EKUAN, G.; HEILMAN, P.; MUIZNIEKS, I.; RUSZAJ, M.; SHURTLEFF B. B.; STRAND, S.; WILMOTH, J.; NEWMANL. A. Phytoremediation of trichloethylene using hybrid Poplar. Environmental Health Perspectives Supplements, v. 106, n. S4, Aug. 1998.

IFB - Institute of Forestry biotechnology, In: Responsible Use: Biotech Tree Principles, Disponível em http://www. responsibleuse.org/material/Responsible_Use_Biotech_Tree_ Principles_v.P.1.0.A.pdf Acessado em 15/05/2010 2010.

JAMES, R.; DIFAZIO, S. P.; BRUNNER, A. M.; STRAUSS S. H. Environmental effects of genetically engineered woody biomass crops, Biomass and Bioenergy, v. 4, n. 4, p. 403-414. 1998. 
JEFFERSON, R. A.; KAVANAGH, T. A.; BEVAN, M. W. GUS fusions: ß-glucuronidase as a sensitive and versatile gene fusion marker in higher plants. EMBO Journal, v. 6, p. 3901-3907, 1987.

JOHNSON, B.; KIRBY, K. Potential impacts of genetically modified trees on biodiversity of forestry plantations: A global perspective. Proceedings of the First International Symposium on Ecological and Societal Aspects of Transgenic Plantations, pp. 176-186. 2001.

KLEIN, T. M.; FITZPATRICK-McELLIGOTT, S. Particle bombardment: a universal approach for gene transfer to cells and tissues. Current Opinion Biotechnology, v. 4, p. 583-590, 1993.

KLEIN, T. M.; WOLF, E. D.; WU, R.; SANFORD, J. C. Highvelocity microprojectiles for delivering nucleic acids into living cells. Nature, v. 327, p. 70-73, 1987.

\section{LI, J.; BRUNNER A. M.; MEILAN R.; STRAUSS, S. H .}

Stability of transgenes in trees: expression of two reporter genes in poplar over three field seasons. Tree physiology v. 29 p. 299-312, 2009.

LUO, K.; DUAN, H.; ZHAO, D.; ZHENG, X.; DENG, W.; CHEN, Y.;STEWART JR, C. N.; MCAVOY, R.; JIANG, X.; WU, Y.; HE, A.; PEI, Y.; LI, Y. 'GM-gene-deletor': fused loxP-FRT recognition sequences dramatically improve the efficiency of FLP or CRE recombinase on transgene excision from pollen and seed of tobacco plants, Plant Biotechnology Journal, v. 5, 263-274, 2007.

MATHEWS, J. H.; CAMPBELL, M. M.; The advantages and disadvantages of the application of genetic engineering to forest trees: a discussion, Forestry, Oxford, v 73, n. 4, 371-380. 2000.

MEILAN, R.; AUERBACH, D. J.; MA, C.; DIFAZIO, S. P.; STRAUSS, S. Stability of herbicide resistance and GUS expression in transgenic hybrid poplars (Populus spp.) during several years of field trials and vegetative propagation.

HortScience, Stanford. vol. 37, n. 2, p. 277-280, apr. 2002.

MURO-ABAD, J. I. Método de melhoramento, assistido por marcadores moleculares, visando a obtenção de híbridos de Eucalyptus spp. 2000. 74f. Dissertação (Mestrado em Genética e Melhoramento) - Universidade Federal de Viçosa, Viçosa, MG.

OWUSU, R. A. GM technology in the forest sector: a scoping study for WWF. 10 p. nov. 1999. Disponível em: http://www. wwf.org.uk/filelibrary/pdf/gmsummary.pdf, Acessado em 15 mar 2010 .

PETERSON, G.; PETERSON, G.; CUNNINGHAM, S.; DEUTSCH, L.; ERICKSON, J.; QUINLAN, A.; RAEZLUNA, E.; TINCH, R.; TROELL, M.; WOODBURY, P.; ZENS S. The risks and benefits of genetically modified crops: a multidisciplinary perspective, Conservation Ecology, v. 4, (1), 13. 2000.

PRAKASH, G.; GURUMURTHI, K. "Genetic transformation and regeneration of transgenic plants from precultured cotyledon and hypocotyl explants of Eucalyptus tereticornis Sm. using Agrobacterium tumefaciens." In vitro cellular \& developmental biology - Plant, v. 45 p. 429-434, 2009.

Pesq. flor. bras., Colombo, v. 31, n. 65, p. 51-61, jan./mar. 2011
QUOIRIN, M.; FRANCHE, C.; KOEHLER, H. "Transient expression of reporter genes introduced in tissues of two Acacia species using a biolistic method." In vitro cellular \& developmental biology - Plant, v. 38, p. 487-492, 2002.

RAUTNER, M. Designer trees. Biotechnology and Development Monitor, v. 44/45, p. 2-7, 2001.

RISHI, A.S.; NELSON, N. D.; GOYAL, A. Improvement of Populus through genetic engineering. Indian Journal Plant Physiology, v. 6, n. 2, p.119-126, 2001.

RUGH, C. L.; SENECOFF, J. F.; MEAGHER, R. B; MERKLE, S. A. Development of transgenic yellow poplar for mercury phytoremediation. Nature Biotechnology, v. 16, p. 925-928, 1998.

SANFORD, J. C.; KLEIN, T. M.; WOLF, E. D.; ALLEN, $\mathrm{N}$. Delivery of substances into cells tissues using a particle bombardment process. Journal Particulate Science Technology, v. 5, p. 27-37, 1987.

SANFORD, J. C.; SMITH, F. D.; RUSSEL, J. A. Optimizing the biolistic process for different biological applications. Methods in Enzimology, v. 217, p. 483-510, 1993.

SANTARÉM, E. R. Métodos eficientes para a transformação genética de plantas. Revista da Ciência \& Tecnologia, Piracicaba, SP, v. 8, n. 15, p. 81-90, jun, 2000.

SARTORETTO, M. L.; SALDANHA, C. W.; CORDER, M. P. M. Transformação genética: estratégias e aplicações para o melhoramento genético de espécies florestais. Ciência Rural, Santa Maria, v. 38, n.3, p. 861-871, mai.jun. 2008.

SERRANO, L. ROCHANGE, F.; SEMBLAT, J. P.; MARQUE, C.; TEULIÈRES, C.; BOUDET. A. M. "Genetic transformation of Eucalyptus globulus through biolistics: complementary development of procedures for organogenesis from zygotic embryos and stable transformation of corresponding proliferating tissue." Journal of Experimental Botany, v. 47 p. 285-290, 1996.

SILVA, R. L. Efeito de plantas transgênicas de Eucalyptus grandis $\mathbf{x} E$. urophylla na propagação clonal, no crescimento, na nutrição e nos indicadores da qualidade biológica do solo. 2009. 60f. Tese (Doutorado em Ciência Florestal) - Universidade Federal de Viçosa, Viçosa, MG.

SPOKEVICIUS, V. A. BEVEREN, K. V.; LEITCH, M. A.; BOSSINGER, G. Agrobacterium-mediated in vitro transformation of wood-producing stem segments in eucalypts. Plant cell reports, v. 23, p. 617-624, 2005.

STRAUSS, S. H. Certification of genetically modified forest plantations, International Forestry Review, v. 3, n. 2, p. 85-102, 2001.

STUDART-GUIMARÃES, C.; LACORTE, C.; BRASILEIRO,

A. C. M. Transformação genética em espécies florestais. Ciência

Florestal, Santa Maria v. 13, n.1, p.167-178, 2003.

SUZUKI, Y.; KAWAZU, T. TSUYAMA, M.; WADA, T.; KONDO, K.; MIZUNO, R.; HARA, T.; KOYAMA, H. Characteristcs of transgenic Eucalyptus hybrids with in overexpression of plant mitochondrial citrate synthase. Nippon Shokubutsu Seiri Gakkai Nenkai oyobi Shinpojiumo Koen Yoshishu, v. 45, p. 107, 2003. 
TANG, W.; NEWTON, R. J. Genetic transformation of conifers and it applications in forest biotechnology. Plant Cell Report, v. 22, p. 1-15, 2003.

THOMAS, S. Ethical and social considerations in commercial uses of food and fibber Crops, Proceedings of the First International Symposium on Ecological and Societal Aspects of Transgenic Plantations, pp. 92-98. 2001

UNEP - United Nations Environment Programme, The potential Environmental, cultural, and socio-economic impacts of genetically modified trees, Convention on Biological Diversity, $13^{\text {th }}$ meeting, Rome, 2008. Disponível em: http://cdn.www.cbd.int/ doc/meetings/sbstta/sbstta-13/information/sbstta-13-inf-06-en.pdf. Acesso em 15 mar. 2010.

VALENZUELA, S. et al. Transgenic trees and forestry biosafety, Electronic Journal of Biotechnology, v. 9, n. 3, Special Issue, 2006
VALENZUELA, S.; STRAUSS, S. Lost in the woods. Nature Biotechnology, 2005, v. 23, n. 5, p. 531-532.

van FRANKENHUYZEN, K.; BEARDMORE, T. Current status and environmental impact of transgenic forest trees, Canadian Journal of Forest Research, v. 34, 1163-1180, 2004.

WANG, G. et al. Poplar (Populus nigra L.) plants transformed with a Bacillus thuringiensis toxin gene: insecticidal activity and genomic analysis. Transgenic Research, v. 5, p. 289-301, 1996.

YEVTUSHENKO, D. P.; SANTOSH, M. "Efficient Agrobacterium-mediated transformation of commercial hybrid poplar Populus nigra L. X P. maximowiczii A. Henry.” Plant cell reports, v. 29 p. 211-221, 2010.

Recebido em 25 de outubro de 2010 e aprovado em 17 de fevereiro de 2011 